\title{
Oxacillin magnetically targeted for the treatment of Methicillin-Resistant $S$. aureus infection in rats ${ }^{1}$
}

\author{
Juliana Fernandes de Carvalho', Ítalo Medeiros de Azevedo', Keyla Borges Ferreira Rocha', Aldo \\ Cunha Medeiros", Artur da Silva Carriço"'
}

'Fellow PhD degree, Postgraduate Program in Health Sciences, Universidade Federal do Rio Grande do Norte (UFRN), Natal-RN, Brazil. Acquisition and interpretation of data, technical procedures, manuscript preparation.

"Full Professor, Chairman, Nucleus of Experimental Surgery, UFRN, Natal-RN, Brazil. CNPq/PQ.2 Fellowship. Conception, design, intellectual and scientific content of the study; analysis and interpretation of data; critical revision.

I'Full Professor, Department of Theoretical and Experimental Physics, UFRN, Natal-RN, Brazil. CNPq/PQ.1D Fellowship. Conception, design, intellectual and scientific content of the study; analysis and interpretation of data; critical revision.

\begin{abstract}
Purpose: To evaluate the effect of oxacillin bonded to magnetic nanoparticles in local infection model in rat.

Methods: Twelve Wistar rats weighing $290 \pm 18 \mathrm{~g}$ were randomly divided into four groups ( $\mathrm{n}=6$, each) and all rats had a magnet ring sutured on their right thighs. In the biodistribution group rats $0.1 \mathrm{~mL}$ of ${ }^{99 \mathrm{~m} T c} \mathrm{c}$-magnetite $(0.66 \mathrm{MBq})$ was injected i.v and after 30 minutes, biodistribution of ${ }^{99 \mathrm{~m} T c-m a g n e t i t e}$ was evaluated in right and left thighs. The other groups were inoculated with MRSA in each thigh muscles. Group 1 rats were injected i.v. with magnetite, group 2 with Magnetite + Oxacillin, group 3 with saline twice a day. After 24 hours samples of muscle secretion were harvested for microbiological analysis; muscle, lungs and kidneys for histology.

Results: ${ }^{99 m} \mathrm{Tc}$-magnetite uptake was three-fold higher in right thigh muscles (with external magnet) than in the left. In magnetite and oxacillin-magnetite groups, bacterial/CFU was significantly lower in thigh muscles than in saline-controls. The inflammatory reaction in muscles and lungs was significantly lower in oxacillin-magnetite group-rats than in other groups $(p<0.001)$.

Conclusion: This study confirms the potential antimicrobial activity of magnetic nanoparticles for Methicillin-Resistant $S$. aureus strains, which in addition to concentrate the antibiotic at the infection site, positively influenced the treatment.
\end{abstract}

Key words: Magnetic Field Therapy. Magnetite Nanoparticles. Methicillin-Resistant Staphylococcus aureus. Rats. 


\section{Introduction}

Staphylococcus aureus (S. aureus) is a common microorganism carried by approximately $30 \%$ of all humans, asymptomatically in their nasopharynx and/or other body sites ${ }^{1}$. It can cause invasive and lifethreatening infections, despite the availability of effective antimicrobial agents to treat diseases such as pneumonia, endocarditis, and septicemia ${ }^{2}$. In general, pathogenical $S$. aureus are the most frequently isolated pathogens from infected biomaterial implant surfaces $^{3,4}$. Over the years, continued selective use of different drugs has resulted in resistance mechanisms that led to multidrug resistance ${ }^{5}$. Methicillin-Resistant S. aureus (MRSA) is one of the bacteria resulting from this selective pressure. It is resistant to a number of widely used antibiotics. Currently, all available B-lactams are considered to be inactive against MRSA strains ${ }^{6}$.

The reduction of efficacy of drugs due to the emergence of resistant microbes makes the treatment more slow and expensive6. One of the most promising strategies for overcoming microbial resistance is the use of nanoparticles (NP)8,9. Several classes of antimicrobial NPs and nanosized carriers for antibiotics delivery have proven their effectiveness for treating infectious diseases, including antibiotic-resistant ones $s^{3,4,8,10}$.

The potential activity of NP comes from their small size and big surface area that can result in the appearance of new mechanical, chemical, electrical, optical, magnetic, electro-optical, and magneto-optical properties3. Studies of magnetic nanomaterials have attracted great interest for the treatment of infections caused by resistant pathogens. The magnetic vector can guide the antibiotic to the site of action and the magnetic field itself can have a deleterious effect on the microorganism, either directly or resulting from changes in the normal environment for the bacterial cell growth.

This study aimed to evaluate the activity of an oxacillin magnetically guided system having magnetite as a vector, in the treatment of MRSA infection induced in rats.

\section{- Methods}

All experiments and procedures were approved by the Institutional Animal Care and use Committee (protocol no 051/2014 CEUA) and handled according to the Brazilian guidelines of care and use involving animals in research.

Wistar rats weighing $290 \pm 18 \mathrm{~g}$ were used. They were supplied by the Vivarium of Center of Health Sciences-UFRN, Brazil. They were divided into four groups ( $n=6 /$ group): the biodistribution group, control group (no infection, no treatment), magnetite group (thigh infection treated with magnetite) and magnetite-oxacillin group (thigh infection treated with magnetite-oxacillin).

\section{Biodistribution of ${ }^{99 m} T c$-magnetite-oxacillin}

In order to study the effect of an external magnet on the biodistribution of magnetite-oxacillin, the biodistribution group rats were anesthetized with ketamine (70 $\mathrm{mg} / \mathrm{Kg}$ ) and xylazine $(7 \mathrm{mg} / \mathrm{Kg}$ ) i.p., and a $\mathrm{Nd}$ magnetic ring (producing a magnetic field of 20 $\mathrm{mT}$ strength at its center) was sutured to the skin on the right thigh. Then $0.1 \mathrm{~mL}$ of ${ }^{99 \mathrm{~m} T \mathrm{~T}-}$ magnetite-oxacillin was injected in the jugular vein, corresponding to $0.66 \mathrm{MBq}$ radioactivity. The injected dose (ID) was calculated as the difference between the measured radioactivity in the syringe before and after injection, using a curiemeter (Capintec CRC-25R). Thirty minutes after injection, animals were euthanized, and right and left thigh muscles were resected. The samples were quickly washed in saline, weighed on a precision balance (Mark $160^{\circledR}$, Bel equipment, Italy) and then introduced into test 
tubes for the determination of biodistribution of ${ }^{99 m}$ Tc-magnetite-oxacillin in an automatic gamma counter (Wizard $1470^{\circledR}$, Perkin-Elmer, Finland). The activity in counts per minute (CPM) in the tissues of interest was calculated as a percentage of the injected dose per gram of tissue (\%ID/g).

\section{Thigh infection model}

An overnight culture of MRSA (CCBH 4395) (courtesy Culture Collection of the Oswaldo Cruz Foundation - Fiocruz/RJ) was washed and resuspended in fresh trypsin soy broth to a concentration of $108 \mathrm{CFU} / \mathrm{ml}$. The animals of magnetite and magnetite-oxacillin groups had both thighs shaved and cleaned with $70 \%$ ethanol; they were then anaesthetized as described above, and injected intramuscularly with a suspension $0.2 \mathrm{~mL}$ of MRSA in both thighs. After this, an Nd-magnetic ring was sutured in each right thigh skin. After 2 and $6 \mathrm{~h}$ of MRSA inoculation, the animals received two i.v. doses of $0.21 \mathrm{mg} / \mathrm{Kg}$ of magnetite and 0.4 $\mathrm{mg} / \mathrm{Kg}$ of oxacillin. The control group received the volume of saline $0.9 \%$. The dosages were chosen on the basis of the possible maximum dose projected for therapy in humans. One day after the infection, the rats were euthanized and the thigh muscles aseptically excised for examination.

\section{Microbiological assay}

After euthanasia, a small incision was performed at each thigh of rats and collection of secretion of muscle was performed for microbiological examination. Samples were homogenized by adding $9 \mathrm{~mL}$ of sterile saline. Serial tenfold dilution was prepared up to $10-9$ from obtained main dilution. All prepared solutions were cultivated at the same time. Blood agar plates for aerobic bacteria were used. All culture plates were evaluated after 48 hours incubation at $37^{\circ} \mathrm{C}$ and the results were recorded as colony forming units/gram (CFU/g).

\section{Histopathology}

Fresh thigh muscles, kidney and lung samples were cut and washed in running water to enable rapid and uniform action of the fixative solution. Then the samples were fixed in $10 \%$ buffered formalin for 48 hours and processed for 18 hours in an automatic tissue processor, using Leica equipment TP 1020, German. Prior to embedding in paraffin, the samples were cut with punch $(6 \mathrm{~mm}$ diameter), for standardization of samples. Histological sections were obtained with microtome Leica RM 2125 RTS, 03 microns thick. The fixed specimens were stained with Prussian blue for detection of iron deposits and hematoxylin/eosin for morphological analysis by optical microscopy, using the CX41 microscope (Olympus, Tokyo, Japan). Sections were examined in magnification power fields (x100) to determine the presence of infiltrating neutrophils, eosinophils, basophils, monocytes and lymphocytes. The total number of cells was analyzed in six fields, for each sample, and expressed in cells per square millimeter. The quantitative analysis was performed using video-assisted software (Image ProPlus 6.0, Media Cyber).

\section{Synthesis of magnetite nanoparticles}

Nanoparticles of magnetite (Fe3O4) with an average particle size of $10 \mathrm{~nm}$ (nanometers) were prepared by high energy milling process. Initially, the metallic Fe and distilled water were put to react in a planetary ball mill (Fritsch Pulverisette 6, Oberstein, Germany) equipped with a stainless steel crucible $45 \mathrm{~cm} 3$ capacity, containing ten balls $10 \mathrm{~mm}$ in diameter according to the stoichiometric reaction:

$3 \mathrm{Fe}+4 \mathrm{H} 2 \mathrm{O} \rightarrow \mathrm{Fe} 3 \mathrm{O} 4+4 \mathrm{H} 2$ 
The equipment was operated in the ratio 1:20 mass/ball, at $300 \mathrm{rpm}$ at 60 -hour cycle. The system was characterized for $x$-ray diffraction, vibrating sample magnetometry, Mossbauer spectroscopy and infrared spectroscopy.

\section{Conjugation of oxacillin to magnetic} nanoparticles

The crystalline oxacillin obtained from Sigma-Aldrich was weighed in a 1:1 drug molecular weight:magnetic particle. The powder was subjected to fragmentation and cold welding of the ball mill operating at 300 rpm for 10 hours with 10 stainless steel balls of $10 \mathrm{~mm}$ diameter and ratio of mass/ball was $1: 20$.

\section{Labeling of Oxacillin/nanoparticles with pertechnetate ( $\left.{ }^{99 m} \mathrm{TcO} 4\right)$}

For the synthesis of ${ }^{99 \mathrm{~m}} \mathrm{TcO} 4-O x a c i l l i n$ + nanoparticles, $100 \mu \mathrm{L}(100 \mu \mathrm{g})$ of stannous chloride $(\mathrm{SnCl} 2.2 \mathrm{H} 2 \mathrm{O})$ were used as reducing agent. $15 \mathrm{mg}$ of Magnetic +Oxacillin nanoparticles were mixed to the solution of stannous chloride and $1000 \mathrm{MBq} / \mathrm{mL}$ of ${ }^{99 \mathrm{~m} T c O} 4$ newly eluted in $1 \mathrm{~mL}$ of $0.9 \%$ saline. This mixture was subjected to vortexing for 10 minutes, after which the solution was ready for immediate use in animals.

\section{Statistical analysis}

Images were measured by pixel density and normalized through the logarithmic transformation. The data of continuous quantitative variables that attended the assumption of normality were expressed as mean \pm standard deviation; those that do not meet the normality are in median (interquartile range). The values of the transformed variables are presented by their respective logarithms. To determine whether the differences between groups are statistically significant, analysis of variance (ANOVA) followed by Tukey multiple comparisons test were used. The nonparametric Wilcoxon test was used to compare the biodistribution of oxacillin labeled with ${ }^{99 m}$ Tc-magnetite between the right and left thigh muscles. The statistical SPSS ${ }^{\circledR} 21$ package was used. The significance level was $5 \%$.

\section{- Results}

\section{Biodistribution of ${ }^{99 m}$ Tc-magnetite-oxacillin}

The biodistribution group had the muscle samples analyzed in a Gama Counter. The quantitative measurements of radiation uptake on muscle samples of the right thigh and left thigh are comparatively shown in Table 1 . The median value of beta radiation counted for right thigh was almost three fold the median value counted for the left thigh, and this difference is statistically significant $(p=0.028)$. So, there was a large concentration of Magnetite $+{ }^{99 \mathrm{~m} T c}$ on the right thigh muscle, where an external magnet was sutured.

\section{Microbiology}

Representative Petri plates are shown in Figure 1. The plates were divided into two halves: the right half of each plate was seeded with secretion of the right thigh muscle (under the effect of external magnet) and the left half with secretion of the left thigh muscle of rats. Figure $1 \mathrm{~A}$ shows that magnetite group rats were protected against bacterial overgrowth in the right thigh muscle in response to treatment with magnetite. Counts taken from the left muscle were greatly (100 to 200 -fold) elevated when compared to the right muscle. Approximately the same values were observed in Magnetite + Oxacillin group rats (Figure 1B). Saline group had approximately a 300fold significant increase in CFUs compared to 
Magnetite and Magnetite + Oxacillin groups. Counts taken from the right thigh muscle of saline group rats did not differ of count from left muscle (Figure 1C).

Table 1 - Descriptive and inferential statistics of biodistribution results of oxacillin labeled with magnetite and ${ }^{99 m} \mathrm{Tc}$. (Values in percentage of injected dose per gram of tissue - \%ID/g).

\begin{tabular}{lccc}
\hline \multirow{2}{*}{ Parameter } & \multicolumn{2}{l}{ Thigh muscle side } & \multirow{2}{*}{-value $^{1}$} \\
\cline { 2 - 3 } & Right (with magnet) & Left & 0.028 \\
\hline Thigh muscle (\%ID/g) & $0.620(1.65)$ & $0.25(0.25)$ & 0.028
\end{tabular}

Median $\left(\mathrm{Q}_{1}-\mathrm{Q}_{3}\right)$

$1-p$-value Wilcoxon test
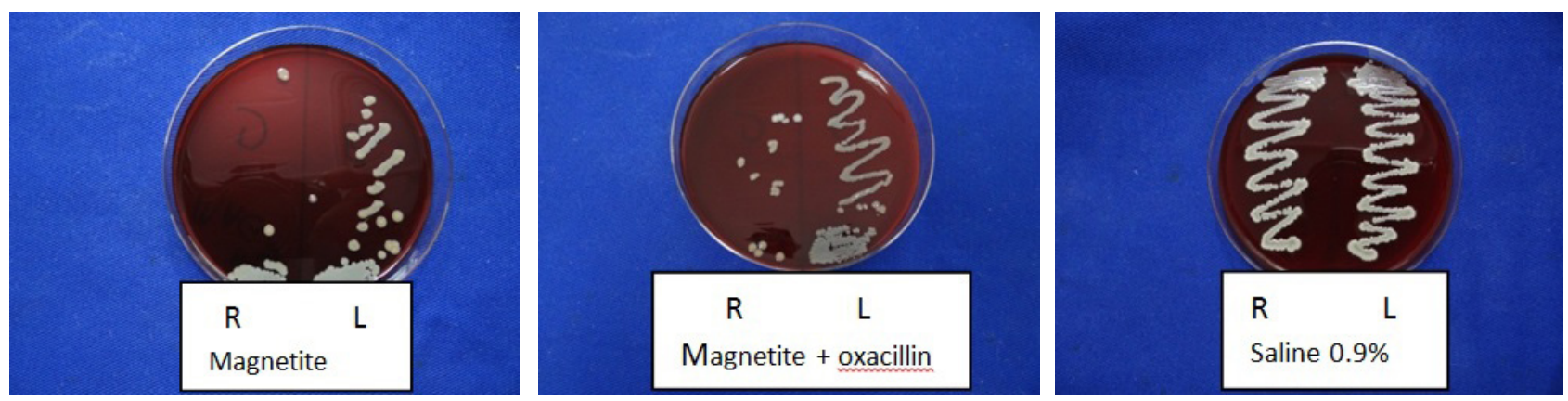

Figure 1 - S. aureus growth: (A) Magnetite group, (B) Magnetite-Oxacillin group and (C) Saline group. "R" means the right thigh muscle and " $L$ " means left thigh muscle. The right side muscle was under the effect of an external magnet.

\section{Histopathology}

Representative microscopic images of right thigh muscle and lung tissue sections from the saline-control, magnetite and magnetite + oxacillin groups are shown in Figure 2. The inflammatory cells were marked using Image ProPlus software. The yellow marked cells were counted in optical density pixels to generate the statistical data of Table 2. For muscle samples, the inflammatory reaction of saline-control group and the magnetite group was significantly higher than of magnetite + oxacillin group $(p<0.001)$. For lung samples the inflammatory reaction was significantly higher in saline-control rats than in magnetite + oxacillin group rats $(p=0.019)$.

Table 2 - Descriptive statistics and inferential results of histopathology per group. Results in density pixels of the inflammatory reaction in right thigh muscle and lung.

\begin{tabular}{lcclc}
\hline \multirow{2}{*}{ Parameter } & Group & & & \\
\cline { 2 - 4 } & Saline-Control & Magnetite & $\begin{array}{l}\text { Magnetite } \\
\text { Oxacillin }\end{array}$ & p-value \\
\hline $\begin{array}{l}\text { Right thigh muscle } \\
\text { (log density pixels) }\end{array}$ & $4.58 \pm 0.32 ¥$ & $4.25 \pm 0.27 \S$ & $3.74 \pm 0.23 ¥ \S$ & $<0.001$ \\
\hline Lung (log density pixels) & $4.79 \pm 0.22 ¥$ & $4.57 \pm 0.12$ & $4.33 \pm 0.31 ¥$ & 0.019 \\
\hline
\end{tabular}

Mean \pm standard deviation

Values in the same line followed by identical symbols are significantly different (ANOVA). 

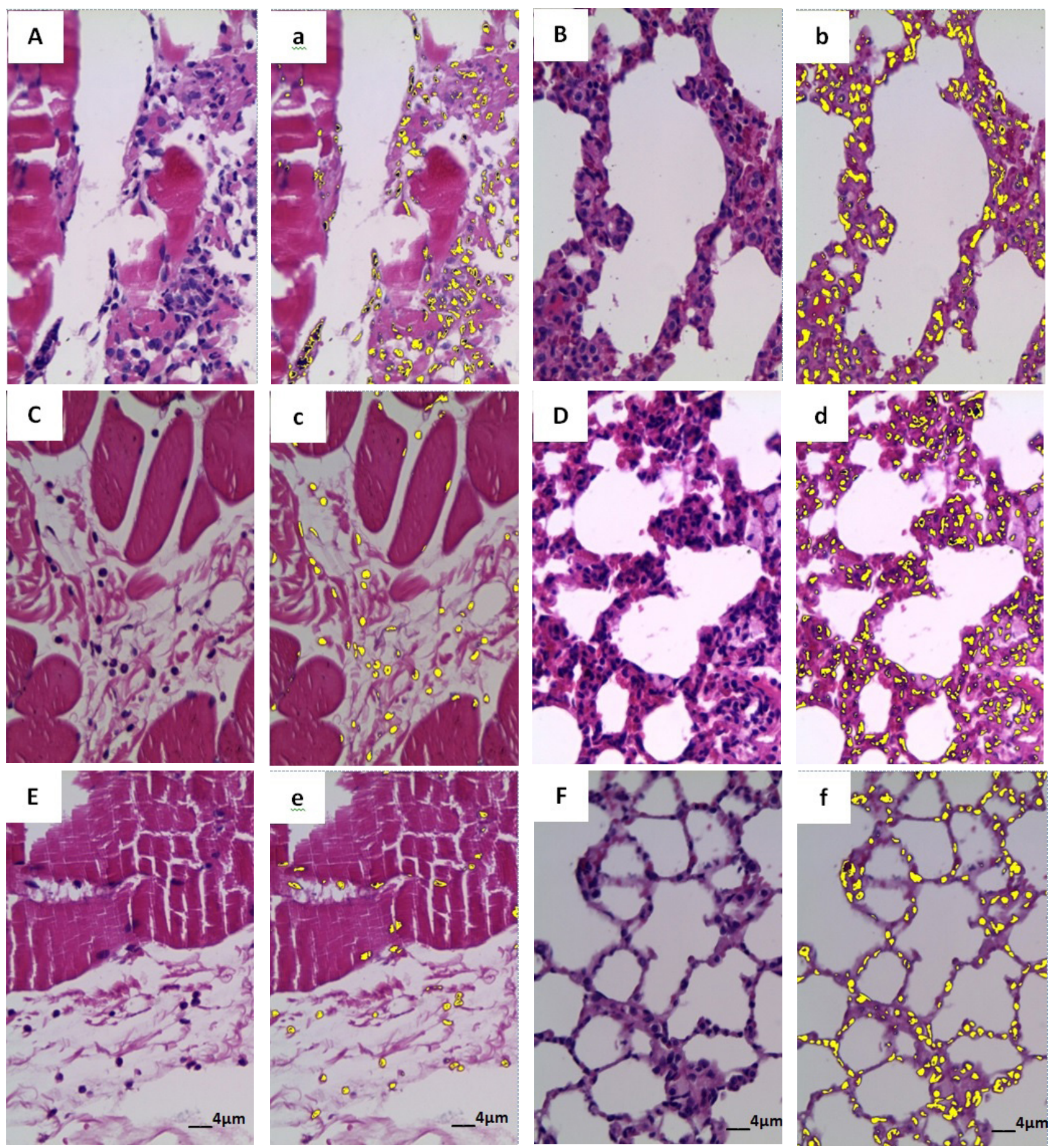

Figure 2 - Haematoxylin and eosin staining $(\times 100)$ of right thigh muscle (Aa,Cc,Ee) and lung (Bb, Dd, Ff) showing leukocyte cell infiltration. In photomicrographs $\mathbf{a}, \mathbf{b}, \mathbf{c}, \mathbf{d}, \mathbf{e}, \mathbf{f}$ the leukocytes were market in yellow using the Image ProPlus software for the cell counting in optical density pixels. $\mathbf{A a}, \mathbf{B b}$ are from saline-control group rats; Cc, Dd from magnetite group, and Ee, Ff from magnetite-oxacillin group.

Histological sections were also examined by Prussian blue staining to detect the presence of Fe-magnetite in specimens.
This staining detected some Fe-magnetite images in lung peribronchial tissues (Figure 3). 

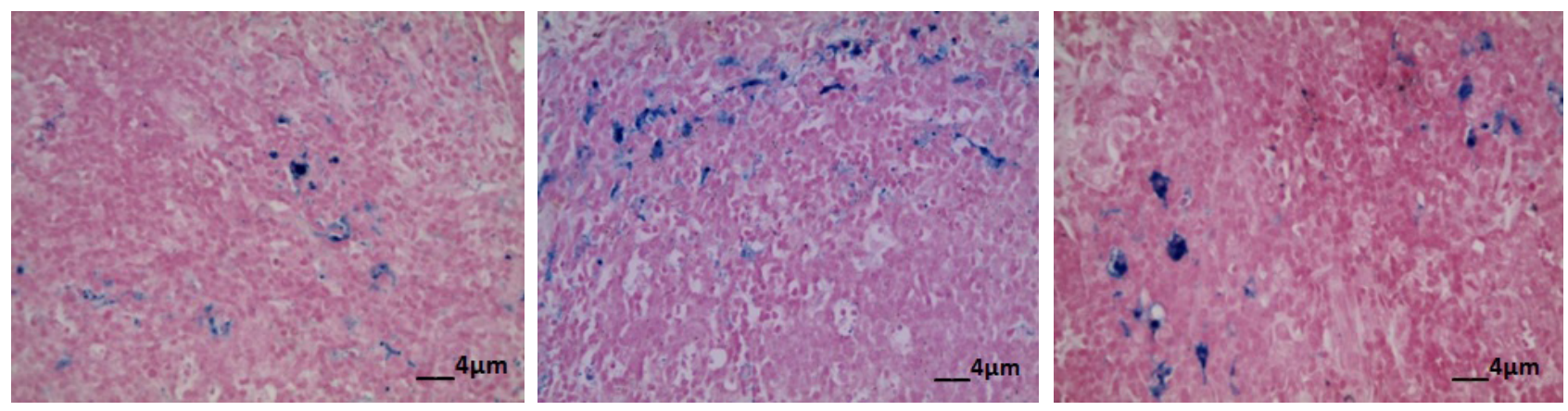

Figure 3 - Photomicrographs of peribronchial areas of lungs showing Fe-magnetite deposits. Prussian blue staining (x100).

\section{- Discussion}

This study was conducted to examine the antimicrobial activity of magnetic nanoparticle and oxacillin magnetic drug delivery system in infected muscle. The study was based on two main approaches: the in vitro testing of oxacillin magnetic drug delivery system for the capacity to stay concentrate on the site of infection despite the systemically administration, and the in vivo testing of oxacillin labeled with the magnetic carrier using an animal model of MRSA thigh infection.

Staphylococcus aureus is one the mains etiologic agents of skin and soft tissue infections ${ }^{11}$. These are common and relatively easy to treat diseases, but the development of resistance in these strains is a great therapeutic problem ${ }^{12}$.

Over the years, the semi-synthetic $\beta$-lactams such as oxacillin, cloxacillin, flucloxacillin were antibiotics of choice for the treatment of $S$. aureus infections ${ }^{13}$. These antibiotics acting by linkage with the penicillin binding proteins (PBPs), resulting in the inhibition of the cell wall synthesis and consequently growth inhibition or cell lysis. MRSA strains synthetize PBP2a, a protein of low affinity to bond $\beta$-lactams, therefore the cell wall can be renewed ${ }^{14}$. A range of new agents for the treatment of MRSA infections have resulted favorably, but usage of antibiotics has enhanced the accumulation of genetic elements coding for resistance, making effective therapies a current challenging goal $^{15,16}$.

Novel therapeutic strategies, such as antibacterial antibodies and cell wall- -specific enzymes as adjunct to antibiotics, are currently being explored ${ }^{17}$. Another alternative is the use of nanotechnology, with delivery systems that concentrate and potentiate the antimicrobial effect ${ }^{15}$. Or even the reuse of drugs, used in traditional therapy, as proposed by Song et al, using a nanoemulsion of chlorhexidine, which seems to have quicker effect on the healing of skin lesions infected with reduced bacterial load and hindering the formation of biofilms ${ }^{18}$.

Our study indicates that the magnetic system which we have developed to deliver oxacillin, holds a promising potential for the treatment of MRSA infections. We have shown that the magnetite-oxacillin nanoparticles are concentrated in the area where the external magnet is placed. As noted in Table 1, in the biodistribution study the system labeled with technetium stayed almost 3 times lower in the left thigh muscle (without the magnet) compared with the concentration found in the right thigh muscle (with the magnet). This result corroborates those found in the study of Grumezescu et al, which also proved the efficacy of magnetic vectorization of drugs ${ }^{19}$. The antimicrobial activity of magnetite-oxacillin nanoparticles may benefit from both the drug concentration at the infection site, as well as from the changes in the normal environment 
for the bacterial cell growth produced by the magnetic field of magnetite nanoparticles. Our results may indicate a possible way for the use of antibiotics currently in disuse due to microbial resistance. These findings may have significant therapeutical implications in the clinical setting.

The histological photomicrographs in rats after injection of test substances showed that lung parenchyma preserved alveolar architecture despite intense cellular infiltration. Infiltration and retention of nanoparticles in human body organs causing inflammatory process is widely described in studies of nanotoxicity. We observed retention of nanomagnetite in lungs. No retention of nanomagnetite was detected in muscle and kidneys. Nanometric particles are small enough to go beyond the blood compartment and due to its large surface area/volume, react with body structures causing toxicity ${ }^{20,21}$. In addition, transition metals such as iron can participate in redox reactions forming free radicals that can lead to oxidative stress and consequent toxicity ${ }^{22}$. Further studies are needed to examine the toxicity of nano-magnetite in lungs. However, the control animals injected with saline solution also showed prominent cellular infiltration in the lung which leads us to believe that the widespread inflammatory reaction is a result of bacterial infection.

An inflammatory process was expected in response to the direct injection of $S$. aureus in the thigh muscles tissue. We have seen a clear difference in the number of inflammatory cells amongst the three animal groups. As shown in Table 2, the count of inflammatory cells was smaller in lungs and muscle of the magnetite and magnetite + oxacillin group rats than in saline-controls.

The microbiological assay clearly showed the favorable effect of magnetite + oxacillin in the infection in the thigh muscle under the effect of an external magnet. Samples of the right thigh muscle, where the magnetic vectorization successfully lead to large concentration of magnetite + oxacillin, had a strong reduction of microbial growth, when compared to samples from the left thigh muscle. Surprisingly, the same antimicrobial effect was observed in the magnetite group (without oxacillin). This result indicates that the magnetic field may also have antibacterial action. Future studies are needed to elucidate the mechanisms of this effect. Azam et al. ${ }^{23}$ reported that this effect is expected, using metal oxide nanomaterials in their work with gram-positive and gram-negative organisms. The bactericidal activity appears to arise from oxidative stress as proposed in studies using metallic nanoparticles ${ }^{24,25}$

\section{- Conclusion}

This study confirms the potential antimicrobialactivity ofmagneticnanoparticles for Methicillin-Resistant S. aureus strains, which in addition to concentrate the antibiotic at the infection site, positively influenced the treatment.

\section{- References}

1. van Belkum A, Melles DC, Nouwen J, van Leeuwen WB, van Wamel $W$, Vos MC,Wertheim HF, Verbrugh HA. Coevolutionary aspects of human colonisation and infection by Staphylococcus aureus. Infect Genet Evol. 2009 Jan;9(1):32-47. doi: 10.1016/j.meegid.2008.09.012.

2. Xiong $\mathrm{MH}$, Bao $\mathrm{Y}$, Yang $\mathrm{XZ}$, Zhu $\mathrm{YH}$, Wang J. Delivery of antibiotics with polymeric particles. Adv Drug Deliv Rev. 2014 Nov 30;78:63-76. doi: 10.1016/j. addr.2014.02.002.

3. Sathyanarayanan MB, Balachandranath $R$, Genji Srinivasulu $Y$, Kannaiyan SK,Subbiahdoss G. The effect of gold and iron-oxide nanoparticles on biofilmforming pathogens. ISRN Microbiol. 2013 Sep 25;2013:272086. doi: $10.1155 / 2013 / 272086$.

4. Subbiahdoss G, Sharifi S, Grijpma DW, Laurent S, van der Mei HC, Mahmoudi 
M,Busscher HJ. Magnetic targeting of surface-modified superparamagnetic iron oxide nanoparticles yields antibacterial efficacy against biofilms of gentamicinresistant staphylococci. Acta Biomater. 2012 Jul;8(6):2047-55. doi: 10.1016/j. actbio.2012.03.002.

5. Alekshun MN, Levy SB. Molecular mechanisms of antibacterial multidrug resistance. Cell. 2007 Mar 23;128(6):103750. PMID: 17382878.

6. Appelbaum PC. MRSA--the tip of the iceberg. Clin Microbiol Infect. 2006 Apr;12 Suppl 2:3-10. Review. PMID: 16524422.

7. Andersson DI, Hughes D. Antibiotic resistance and its cost: is it possible to reverse resistance? Nat Rev Microbiol. 2010 Apr;8(4):260-71. doi: 10.1038/nrmicro2319.

8. Hajipour MJ, Fromm KM, Ashkarran AA, Jimenez de Aberasturi D, de Larramendi IR, Rojo T, Serpooshan V, Parak WJ, Mahmoudi M. Antibacterial properties of nanoparticles. Trends Biotechnol. 2012 Oct;30(10):499511. doi: 10.1016/j.tibtech.2012.06.004.

9. Pelgrift RY, Friedman AJ. Nanotechnology as a therapeutic tool to combat microbial resistance. Adv Drug Deliv Rev. 2013 Nov;65(13-14):1803-15. doi: 10.1016/j. addr.2013.07.011.

10.Huh AJ, Kwon YJ. "Nanoantibiotics": a new paradigm for treating infectious diseases using nanomaterials in the antibiotics resistant era. J Control Release. 2011 Dec 10;156(2):128-45. doi: 10.1016/j. jconrel.2011.07.002.

11.Dryden MS. Complicated skin and soft tissue infection. J Antimicrob Chemother. 2010 Nov;65 Suppl 3:iii35-44. doi: 10.1093/ $\mathrm{jac} / \mathrm{dkq} 302$.

12.Stevens DL, Bisno AL, Chambers HF, Dellinger EP, Goldstein EJ, Gorbach SL,Hirschmann JV, Kaplan SL, Montoya JG, Wade JC. Practice guidelines for the diagnosis and management of skin and soft tissue infections: 2014 update by the infectious diseases society of America. Clin Infect Dis. 2014 Jul15;59(2):147-59. doi: 10.1093/cid/ ciu296.

13.Negi B, Kumar D, Kumbukgolla W,
Jayaweera S, Ponnan P, Singh R, Agarwal S, Rawat DS. Anti-methicillin resistant Staphylococcus aureus activity, synergism with oxacillin and molecular docking studies of metronidazole-triazole hybrids. Eur J Med Chem. 2016 Jun 10;115:426-37. doi: 10.1016/j.ejmech.2016.03.041.

14.Otero LH, Rojas-Altuve A, Llarrull LI, Carrasco-López C, Kumarasiri M, Lastochkin $E$, Fishovitz J, Dawley $M$, Hesek D, Lee $M$, Johnson JW, Fisher JF, Chang M, Mobashery $S$, Hermoso JA. How allosteric control of Staphylococcus aureus penicillin binding protein $2 a$ enables methicillin resistance and physiological function. Proc Natl Acad Sci USA. 2013 Oct 15;110(42):16808-13. doi: 10.1073/pnas.1300118110.

15.Balaure PC, Popa RA, Grumezescu AM, Voicu G, Rădulescu M, Mogoantă L, Bălşeanu TA, Mogoşanu GD, Chifiriuc MC, Bleotu C, Holban AM, Bolocan A. Biocompatible hybrid silica nanobiocomposites for the efficient delivery of anti-staphylococcal drugs. Int J Pharm. 2016 Aug 30;510(2):53242. doi: 10.1016/j.ijpharm.2016.03.037.

16.Liakos I, Grumezescu AM, Holban AM. Magnetite nanostructures as novel strategies for anti-infectious therapy. Molecules. 2014 Aug 20;19(8):12710-26. doi: 10.3390/molecules190812710.

17.Rasmussen RV, Fowler VG Jr, Skov R, Bruun NE. Future challenges and treatment of Staphylococcus aureus bacteremia with emphasis on MRSA. Future Microbiol. 2011Jan;6(1):43-56. doi: 10.2217/ fmb.10.155.

18.Song $Z$, Sun $H$, Yang $Y$, Jing $H$, Yang $L$, Tong Y, Wei C, Wang Z, Zou Q, Zeng H.Enhanced efficacy and anti-biofilm activity of novel nanoemulsions against skin burn wound multi-drug resistant MRSA infections. Nanomedicine. 2016Aug;12(6):1543-55. doi: 10.1016/j.nano.2016.01.015.

19.Grumezescu AM, Gestal MC, Holban AM, Grumezescu V, Vasile BS, Mogoantă L, lordache F, Bleotu C, Mogoșanu GD. Biocompatible Fe3O4 increases the efficacy of amoxicillin delivery against Gram-positive and Gram-negative bacteria. Molecules. 
2014 Apr 22;19(4):5013-27. doi: 10.3390/ molecules19045013.

20.Fu PP, Xia Q, Hwang HM, Ray PC, Yu H. Mechanisms of nanotoxicity: generation of reactive oxygen species. J Food Drug Anal. 2014 Mar;22(1):64-75. doi: 10.1016/j. jfda.2014.01.005.

21.Oberdörster G, Oberdörster E, Oberdörster J. Nanotoxicology: an emerging discipline evolving from studies of ultrafine particles. Environ Health Perspect. 2005 Jul;113(7):823-39. PMID: 16002369.

22.Yin JJ, Fu PP, Lutterodt $H$, Zhou YT, Antholine WE, Wamer W. Dual role of selected antioxidants found in dietary supplements: crossover between anti- and pro-oxidant activities in the presence of copper. J Agric Food Chem. 2012 Mar14;60(10):2554-61. doi: 10.1021/jf204724w.

23.Azam A, Ahmed AS, Oves M, Khan MS, Habib SS, Memic A. Antimicrobial activity of metal oxide nanoparticles against Gram-positive and Gram-negative bacteria: a comparative study. Int J Nanomedicine. 2012;7:6003-9. doi: $10.2147 /$ IJN.S35347.

24.Auffan M, Rose J, Wiesner MR, Bottero JY. Chemical stability of metallic nanoparticles: a parameter controlling their potential cellular toxicity in vitro. Environ Pollut. 2009 Apr;157(4):1127-33. doi: 10.1016/j. envpol.2008.10.002.

25.Feng QL, Wu J, Chen GQ, Cui FZ, Kim TN, Kim JO. A mechanistic study of the antibacterial effect of silver ions on Escherichia coli and Staphylococcus aureus. J Biomed Mater Res. 2000 Dec 15;52(4):662-8. PMID: 11033548.

\section{Acknowledgements}

The technical support of the Department of Pathology, and the Service of Microbiology of Onofre Lopes University Hospital-UFRN.

\section{Correspondence:}

Juliana Fernandes de Carvalho

Rua General Cordeiro de Faria, $\mathrm{s} / \mathrm{n}$

59012-570, Natal, RN, Brazil

carvalho.jf.2918@gmail.com

Conflict of interest: none

Financial sources: CNPq (Grant 4449083/2014-4) and CAPES.
Received: Sep 05, 2016

Review: Nov 07, 2016

Accepted: Dez 09, 2016

${ }^{1}$ Research performed at Laboratory of Magnetism and Magnetic Materials and Nucleus of Experimental Surgery, Department of Surgery, Universidade Federal do Rio Grande do Norte (UFRN), Brazil. Part of PhD degree thesis, Postgraduate Program in Health Sciences. Tutor: Prof. Dr. Artur da Silva Carriço. 